
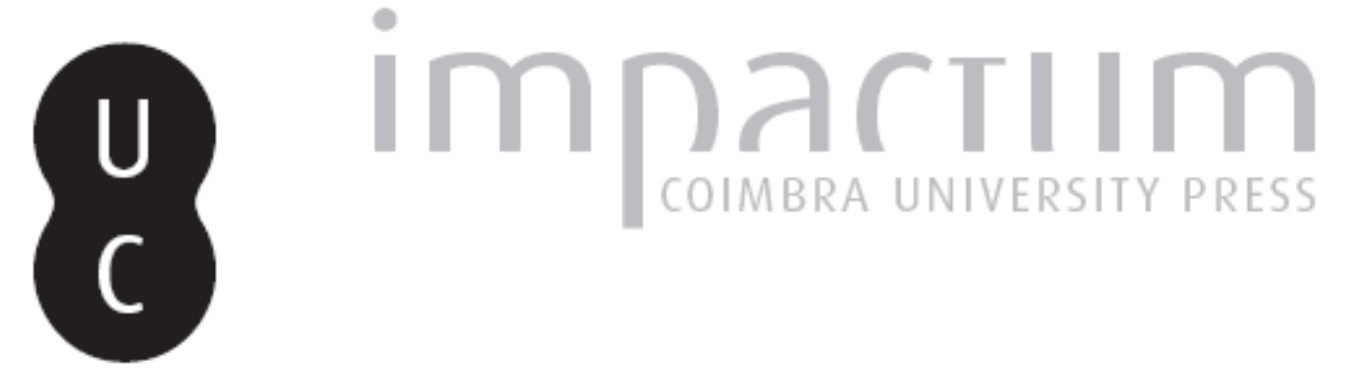

\title{
Antonio Sérgio, Bernardino Machado e as Memórias de Raul Brandão: correspondểncia inédita
}

Autor(es): $\quad$ Baptista, Jacinto

Publicado por: Imprensa da Universidade de Coimbra

URL persistente:

URI:http://hdl.handle.net/10316.2/45060

DOI:

DOI:https://doi.org/10.14195/2183-8925_5-2_4

Accessed : $\quad$ 26-Apr-2023 12:06:23

A navegação consulta e descarregamento dos títulos inseridos nas Bibliotecas Digitais UC Digitalis, UC Pombalina e UC Impactum, pressupõem a aceitação plena e sem reservas dos Termos e Condições de Uso destas Bibliotecas Digitais, disponíveis em https://digitalis.uc.pt/pt-pt/termos.

Conforme exposto nos referidos Termos e Condições de Uso, o descarregamento de títulos de acesso restrito requer uma licença válida de autorização devendo o utilizador aceder ao(s) documento(s) a partir de um endereço de IP da instituição detentora da supramencionada licença.

Ao utilizador é apenas permitido o descarregamento para uso pessoal, pelo que o emprego do(s) título(s) descarregado(s) para outro fim, designadamente comercial, carece de autorização do respetivo autor ou editor da obra.

Na medida em que todas as obras da UC Digitalis se encontram protegidas pelo Código do Direito de Autor e Direitos Conexos e demais legislação aplicável, toda a cópia, parcial ou total, deste documento, nos casos em que é legalmente admitida, deverá conter ou fazer-se acompanhar por este aviso.

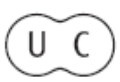




\section{REVISTA DE HISTÓRIA DAS IDEIAS 5}

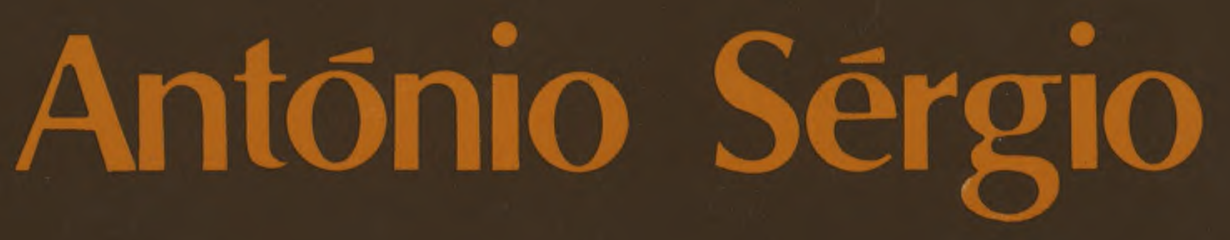

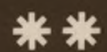

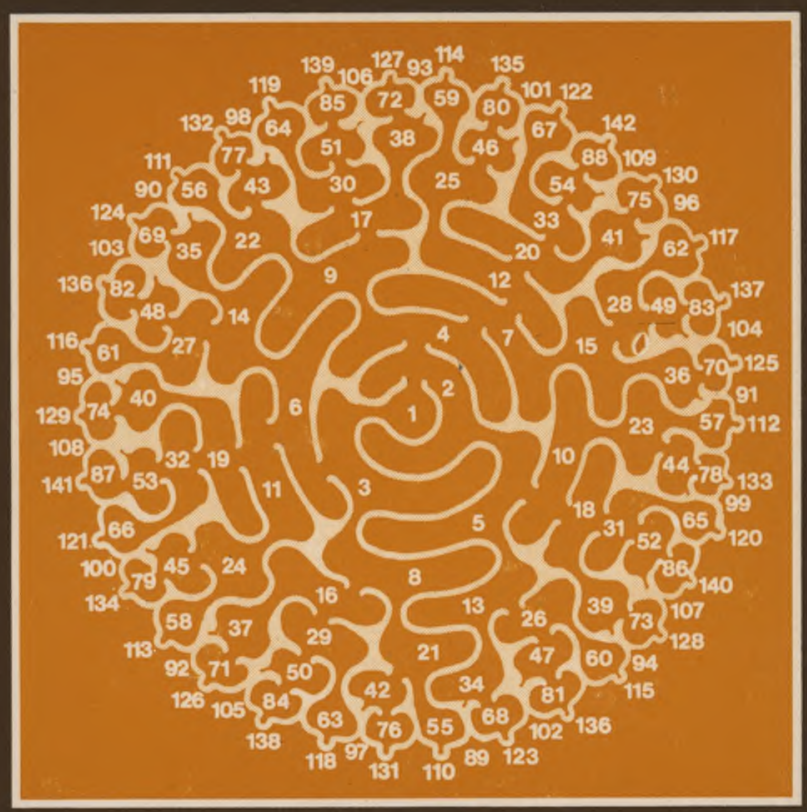

INSTITUTO DE HISTÓRIA E TEORIA DAS IDEIAS FACULDADE DE LETRAS

COIMBRA 1983 


\title{
ANTONIO SÉRGIO, BERNARDINO MACHADO E AS MEMórIa S DE RAUL BRANDÃO
}

\author{
Correspondência inédita
}

Um livro de Raul Brandão, concluído pelo escritor no final da vida e só publicado em 1933 (Vale de Josafat, terceiro volume das Memórias), é o motivo fulcral da troca de cartas, do mesmo ano, de duas notáveis personalidades de Portugal contemporâneo-António Sérgio e Bernardino Machado que hoje aqui tornamos públicas pela primeira vez.

Em resumo, nesta correspondência, António Sérgio (1883-1969), parecendo responder a um primeiro reparo do ex-presidente, provavelmente contido em carta que não conhecemos, dá-lhe conta das circunstâncias que levaram a Seara Nova a publicar aquele livro póstumo do autor de Os Pobres; Bernardino Machado (1851-1944) replica (se, realmente, a carta de Sérgio precede a sua), estranhando (voltando a estranhar?) que a Seara tenha editado tal livro, que ultrapassa o limite moral e no qual Raul Brandão conta anedotas falsas, algumas das quais não podem infelizmente ser desmentidas pelas pessoas a quem diz que as ouviu.

A permissiva filosofia em que se terá abonado Raul Brandão (1867-1930) para se decidir a publicar ou a deixar para publicação post-mortem as suas irreverentes memórias encontramo-la expressa numa página do próprio Vale de Josafat.

Antes, porém, de desbravarmos terreno, seguindo este trilho, lembremos que a alusão bíblica contida no título da obra memorialista se refere à profecia de Joel segundo a aual o Senhor juntaria todas as gentes no Vale de Josafat (lugar do iuízo final?) para aí julgar os inimigos de Sião. Não se cuide, no entanto, que o escritor pretende assumir-se juiz dos seus contemporâneos que povoam o Vale; se não erramos,

\footnotetext{
* Jornalista e Historiador.
} 
ele, que foi jornalista profissional, só quer ser o relator (o repórter?) do espectáculo, feito de grandezas e de misérias, que é a vida, inescapavelmente envolvente, e comprometedora, mesmo para o observador que se pretende neutro-e Raul Brandão não era, e talvez nem quisesse ser, neutro: debaixo da sua bonomia aparentemente compassiva tumultuavam a parcialidade e a paixão.

Refiramos, então, a filosofia do memorialismo de Brandão. Num capítulo do Vale de Josafat significativamente (comprometedoramente?) intitulado "A mentira», o escritor conta que Guerra Junqueiro, «antes da morte, mas já perto da morte», lhe pediu para retirar das Memórias algumas anedotas que lhe tinha contado sobre o rei D. Carlos. Porquê? - interroga-se a benévola e, ao mesmo tempo, amoral alma que é o autor de Húmus. E logo responde que Junqueiro «não teve talvez a coragem de dizer desassombradamente que não eram verdadeiras, nem é fácil tê-la diante dos homens»».

E aí está, pois, a terrível filosofia que leva Raul Brandão a expor factos controversos e de fundamento duvidoso nas páginas dos seus livros de memórias, como se fosse nas colunas de um jornal sensacionalista (não esqueçamos - repetimo-lo - que ele foi profissional de jornalismo, além de militar, embora relutante; que conheceu não só a tarimba dos quartéis como a tarimba das redacções, ambas rudes e impiedosas). Num rebate de consciência, professa mesmo uma espécie de «mea culpa» quando escreve: « $i$ Quantas vezes nos deixamos arrastar, fazendo um dito sobre um amigo, exagerando um quadro ou inventando um pormenor?» Mas logo, cínico empedernido - a si próprio se absolve: «Quem é que diz a verdade nua e crua? Todos compõem, cada qual segundo o seu interesse. Só com a verdade extrema talvez não fosse possível a política, a literatura e a própria vida».

E agora chegada a altura de recuperarmos o eco dos Factos e Documentos a que António Sérgio alude na sua carta, e que se publicou, efectivamente, no n. 348 da Seara Nova (22 de Junho de 1933):

\section{«VALE DE JOSAFAT»}

«Houve quem explorasse politicamente, houve até quem se afligisse, com certos lances anedóticos do Vale de Josafat de Raul Brandão. Não tomemos a cousa ao trágico, e mantenhamos o sentido das proporções. Uma parte da obra de Raul Brandão é feita de páginas alucinadas, que logram impressio- 
nar o leitor sensível pelo exagero fantástico do claro-escuro. Um fantástico com efeito, era ou quis ser o seu autor: um visionário, um caricaturista, uma espécie de Goya das águas-fortes. Ninguém procurará nas suas memorias a verdade objectiva dos acontecimentos, mas as reacções nervosas de um grande satírico; não é aquilo um livro de historia, mas de pura arte. Ao primeiro instante, pode ter-se o ímpeto de o desmentir; a intervenção do bom-senso, porém, dir-nos-á que protestar contra a sátira viva, desmenti-la, corrigi-la, seria tão absurdo, por exemplo, como uma pessoa caricaturada que viesse declarar ao respeitável público: «eu, meus senhores, sou mais bonito, mais regular de proporções, do que o caricaturista me desenhou». As $\mathrm{Me}$ mórias de Raul Brandão são a caricatura de uma época: e fazer correctivos (cremos nós) será o cúmulo da ingenuidade».

Este pequeno texto sergiano é como que um resumo da explicação a que Sérgio alude na sua carta e que Câmara Reis publicou no Diário Liberal, a 6 de Junho de 1933, sob a rubrica genérica «Homens e Ideias», mais tarde reproduzido na secção de «Factos e Documentos» da Seara n. $^{\circ}$ 350, de 10 de Agosto de 1933, aliás sem indicação de procedência. Na sua explicação, o director da Seara, revela-se ciente dos engullios, mesmo indignação, que o livro estava a provocar nas hostes da oposição republicana à ditadura, as quais não veriam asado o momento para a exposição de factos e opiniões controversos e desprimorosos para o regime derrubado e vilipendiado pelos ditadores do 28 de Maio. Como que a deitar água na fervura republicana, Câmara Reis escreve no Diário Liberal que Vale de Josafat «não é a obra dum político - ele declara que nunca o foi - nem dum doutrinário, mas sim dum homem de letras e, até certo ponto, dum historiador». Ainda segundo o articulista, Brandão concebia a história «à maneira de Michelet, como uma ressurreição. Mas uma ressurreição realizada por vezes numa atmosfera alucinada e apaixonada»». A par destas explicações subjectivas, desvenda Câmara Reis alguns factos que merecem reter-se. Assim, Brandão demorara propositadamente a publicação deste volume, porque «receava exacerbar as agruras de alguns vencidos». A viúva do escritor, D. Maria Angelina Brandão, tivera durante anos «a mesma hesitação e o mesmo escrúpulo». Tomara a peito acompanhar a publicação dos inéditos do marido, empenhando-se em «fazer a revisão escrupulosa das provas» (tarefa cujos re- 
sultados, diga-se de passagem, apresenta não poucas falhas, que um profissional competente não cometeria). Essa missão, somada à «de se construir um mausoléu digno do autor do Húmus consome toda a energia do seu espírito enlutado e ardente». Mas talvez a explicação mais convincente seja a de que «esta obra-prima de observação, de ironia, de ternura e de sarcasmo, mais tarde ou mais cedo teria de ser publicada». Assim sendo, «melhor é que o seja antes de desaparecerem os que porventura forem atingidos pelas suas páginas satíricas, mas raramente cruéis»».

No mesmo Diário Liberal, duas semanas depois, a 20 de Junho, M. S. (Mário Salgueiro?), não desistindo de apreciar criticamente Vale de Josafat e acaso não se satisfazendo com a explicação de Câmara Reis, classificava a obra de Brandão como «um livro triste» (título do seu artigo) e escrevia, designadamente: "Livros como o de Raul Brandão fazem.... esmorecer e duvidar. E nós temos de criar e alimentar uma certeza- nem que seja à custa de nós mesmos, do nosso sangue e da nossa vida».

Bernardino Machado não podia deixar de sentir-se magoado ao 1er, por exemplo, que Raul Brandão, apoiado num recorte de O Primeiro de Janeiro de Julho de 1911, lhe atribuía um procedimento menos consentâneo com a dignidade das funções de ministro dos Negócios Estrangeiros, que naquela data exercera. Tomando como boa a informação do diário do Porto, o autor de Vale de Josafat repete-a sem uma palavra de desagravo em relação ao ilustre correligionário:

«Perante a atitude do governo espanhol, que pouca ou nenhuma consideração ligava às reclamações do governo português relativas à permanência, na fronteira, dos conspiradores e traidores à Pátria, entendeu o sr. Bernardino Machado dever oficiar ainda uma vez ao governo do sr. Canalejas, mas em termos menos doces do que os usados até aí. Para cobrar coragem mostrou a sua nota ao ministro inglês, que, particularmente, a achou bem. Apenas enviada, tornou o sr. ministro dos estrangeiros conhecida do governo espanhol a aprovação do ministro inglês, que, ignorando a inconfidência que o atingia, recebeu do seu governo, com surpresa e mágoa, ordem de retirada, em 24 horas, não obstante a sua saúde não ser, nesse momento, das mais invejáveis...»

Esta a primeira, contundente, referência do Vale de Josaiat ao eminente estadista, último Presidente da I República. As referências seguintes, puramente anedóticas, nem colocavam mal (ou tão mal) Bernardino Machado, uma vez que, bem feitas as contas, só especulavam, caricaturalmente, em torno de traços característicos, no fundo não desfavorá- 
veis, da forte personalidade do autor das Notas de um Pai - a cordialidade, a afabilidade, democraticamente distribuida. E a rijeza de constituição: «É um homem de aço». Mas, pela boca de um terceiro (o verrinoso Junqueira, falecido em 1923), o estadista, dito "de ferro», é assim retratado, sem complacência, antes com o fito de, através da caricatura, se obter um efeito cómico:

«- De ferro? De borracha é que ele é. Pode passar-lhe um cilindro de estrada por cima que ele levanta-se logo, todo lépido, a tirar o chapéu».

Mas o autor do Vale de Josafat, ficcionista arrastado pela vertigem de criar ou avivar o perfil de personagens, mesmo à custa da verosimilhança e da verdade, não se limita a retratar Bernardino Machado como um homem de ferro ou de aço. No livro póstumo, é inconveniente, deselegante, desrespeitoso, para com o simpático estadista, de quem caricaturalmente, impiedosamente, malevolamente, escreve:

«Cansa toda a gente, extenua toda a gente - e teima até à morte. Promete tudo - falta a tudo. Não faz nem deixa fazer. Mas, como um velho moinho de café, não cessa de moer e remoer palavras sobre palavras»».

Um traço de verdade, afinal, nesta verrina: o da teima até à morte - teimosia que nobilitou o homem que, até ao fim dos seus muitos anos de vida, teimou em não se vergar à ditadura.

Quanto ao diálogo entre Bernardino Machado e António Sérgio a que o ex-Presidente indirectamente se refere na sua carta - o próprio Raul Brandão o classifica como «anedota, que é posterior, fica aqui bem, completa o retrato»:

«Noutro dia, a conversar com o António Sérgio, disse-lhe [Bernardino Machado]:

«Meu amigo: é preciso fazer-se quanto antes uma reforma de instrução primária profunda.

«-Também assim o entendo.

«-É da maior urgência. É básico.

«-É esse o meu pensamento.

«Imagine que noutro dia minha neta chegou-se à minha beira e disse-me: - Ó avó: ¿ o Sidónio foi presidente? - Presidente? Nunca! - Mas neste livro em que estudo, vem que o Sidónio foi presidente, como o avô. - Ora veja o senhor António Sérgio que compêndios! que instrução! que professores!... É preciso fazer-se, quanto antes, uma grande reforma. Mas profunda».

Esta (anedota) não tem mesmo pés nem cabeça-, nem António Sérgio, na sua correspondência com o estadista, pro- 
vavelmente, perderá tempo a mencioná-la ou a protestar que a desmentirá na primeira oportunidade. Só por bravata (que, aliás, seria defensável, como profíssão de fé democrática, legalista), Bernardino Machado, Presidente eleito pelo Congresso da República, ignoraria ter Sidónio Pais ocupado, na Presidência, o lugar que fora, legítimamente, o seu. Talvez a anedota, como tal entendida por Raul Brandão, fosse, afinal, a expressão caricatural da dolorida, paradoxalmente significativa ironia do estadista que firmemente se recusou a ceder perante a violência e, coerentemente, não transmitiu os poderes presidenciais a Sidónio Pais, figura de proa da revolução reaccionária de 5 de Dezembro de 1917. E, por isso, foi preso, destituído, e banido do País, conhecendo o amargor do exílio.

A dolorosa experiência do exílio tê-la-ia de novo Bernardino Machado quando da sua renúncia presidencial, logo após o 28 de Maio. No seu folheto A Política e o Poder Militar, que publicou em 1926, Bernardino afirma ter «a certeza de que os republicanos que, com Cabeçadas, na sua exaltação revolucionária, promoveram o 28 de Maio, não pensaram jamais em instituir sobre nós a ditadura militarista, irmã gémea da ditadura clerical». Na importante Declaração com que finaliza o seu onúsculo, o estadista afirma:

"Quando transmiti os poderes presidenciais, fi-lo a um chefe de governo, de coração republicano, que eu sabia bem que se propunha restaurar o mais breve possível a ordem constitucional. Aos seus sucessores eu não os transmitiria. Até para não sujeitar a nação ao pungentíssimo desdoiro de ver à sua frente um poder militarista, a invocar a Constituição perante os estrangeiros, não se importando nada com ela perante os seus concidadãos, como se não houvesse entre nós um povo soberano».

E, mais adiante, comenta:

«Foi um grande mal que se não constituísse, logo à primeira hora, contendo a marcha sobre Lisboa, um governo nacional de homens públicos de toda a confiança da República, como felizmente temos dentro e fora dos partidos, que nos preparassem sem mais abalos, uma rápida solução legal, garantindo a todas as nossas forças políticas a sua livre representação».

São demonstrativas da rijeza da sua têmpera, as últimas, belas, palavras da declaração de Bernardino:

«A ditadura é congénere da Monarquia. Quem diz democracia, diz liberdade. E, enquanto a não recobrarmos, não estamos em República». 
O 28 de Maio é, também, o objecto de uma interessante nota do punho de Bernardino Machado encontrada no seu espólio e que diz:

«Fiz tudo por conter a onda que vinha atrás de Gomes da Costa, contando subir ao poder sobre os seus desastramentos. E ainda estou convencido de que se Cabeçadas se desenleasse dos seus excessivos escrúpulos de camaradagem com Gomes da Costa e organizasse de pronto o ministério, como tanto the aconselhei instantemente, o poder civil evitaria o movimento militarista».

Bernardino, homem de aço! Vem a propósito recordar que foi Bordalo quem caricaturou Hintze Ribeiro e Bernardino Machado com as incisivas fórmulas saídas do seu incomparável buril: o primeiro aço por fora e caniço por dentro, o segundo caniço por fora e aço por dentro.

Reconheça-se que só podia ter sido, como atrás se disse, uma personalidade muito forte o homem de quem, com crueldade típica de um criador de ficção (e de um jornalista não muito agarrado ao real), Brandão põe dentro desta moldura cómica:

«No ministério dos negócios estrangeiros ainda hoje se fala com espanto e terror nesse homem que só ao romper da manhã levava os secretários, meio mortos, para casa, cumprimentando ainda ao sair, com afabilidade, os puxadores das portas - e dos ovos estrelados que ele lá esqueceu entre a papelada oficial e que, com o leite, constituem toda a sua alimentação».

Já vimos a explicação que, no próprio Vale de Josafat, Raul Brandão dá do memorialismo fantasioso. Com o valioso auxílio do prof. J. Machado Vaz, que gentilmente nos facultou as duas cartas inéditas para divulgação pública, sempre fiel ao princípio de que é «dever de quantos têm em seu poder documentos que podem lançar luz sobre personalidades e factos da nossa História colocá-los ao dispor dos estudiosos»», vejamos agora, extraídas do livro onde Oliveira Marques coli-' giu os Manifestos Políticos (1927-1940), de Bernardino Machado, a opinião do consequente estadista sobre os memorialistas em geral:

Página 484: «Alguns lidadores chegaram mesmo em memórias póstumas ao sadismo dos ataques mais destoantes das suas corajosas vidas». E na página 512: «Fiz inquebrantavelmente a campanha de atracção entre os meus correligionários. Muitas vezes tive de calar a minha própria sensibilidade magoada por alguns - e tenho ainda hoje, vituperado por malévolas memórias póstumas - para fazer justiça aos grandes serviços desses mesmos». 
É certo que Bernardino Machado, ao longo dos seus escritos, foi também memoralista, como notou Júlio Brandão, mas, assoberbado pelo seu contínuo combate panfletário, não deixou senão algumas notas para Memórias. Sabe-o bem o prof. Machado Vaz, até por dois trechos de cartas que o avô lhe dirigiu e que aquele nosso amigo teve a amabilidade de transcrever, facultando-no-los para este nosso trabalho. De Paredes de Coura, 5.12.1941 — «Tens toda a razão, e quanto te agradeço também! no que dizes das minhas memórias, isto é das memórias que alguns homens aliás cultos, esquecendo-se de si próprios, escreveram contra mim para ser publicado postumamente. E não falo das memórias do Cabral, cuja insolência faz delas páginas por vezes tão odiosas como odientas. A minha pena é que, até pelas tuas imperativas obrigações, as nossas conversas se interrompam tantas vezes e com elas os teus extremosos ocios de meu memoralista».

E ainda de Paredes de Coura, 13.1.1942 — «E não só já me basta de sacrifícios de toda a espécie para restabelecer a continuidade da minha vida particular, depois de tantos anos de exílio, mas até o teu gentil rebate, lembrando alguns incidentes da minha vida pública, me faz pensar que devo concentrar as forças que me restam, senão para lutar pelo futuro, ao menos para dizer do passado e dos seus homens, no meu lar, na minha vida académica de estudante e de professor, e na minha vida pública tão acidentada, aquilo que lhes devi. E um acto de gratidão que me cumpre não adiar mais».

E o prof. Machado Vaz diz-nos, ainda, a propósito das Memórias: «Se meu Avô as tivesse redigido, elas seriam, como me escreveu, o tal «acto de gratidão» e nunca as verrinas que, desgraçadamente, alguns dos republicanos nos legaram. Na verdade, como se sabe, o Diário de João Chagas, a CorresponcLêncva de Teixeira Gomes e as fantasias de Raul Brandão, foram aproveitadas, gulosamente, pelos inimigos da República, no ataque aos seus Homens mais representativos. Bernardino Machado e Afonso Costa foram os alvos nreferidos. Essas demonstrações de complexos, mais ou menos aliteratados, são ainda hoje o viático de certos «analistas» que medem os estadistas da República pela quase geral mediocridade dos políticos que aí temos. Assim se continua a campanha de calúnias forjada intencionalmente pela Ditadura».

Um derradeiro apontamento dar-nos-á ensejo de, por um lado, referir aquilo que António Sérgio pensava de Raul Brandão como criador literário e, por outro lado, mostrar um esquema de abordagem da obra de imaginação, em geral, tal como a pratica um paladino da «ideia clara» como o autor dos Ensaios. Na sua apreciação crítica dos Pescadores 
de Brandão, primeiramente aparecida na revista Lusitânia, em 1924, e depois recolhida no terceiro volume dos Ensaios, Sérgio começa por definir duas grandes famílias de espíritos: aqueles «em que predomina a nebulosa», os espíritos «musicais» e aqueloutros «onde na nebulosa turbilhonante.... se destaca o núcleo do pensar definido, do encadeamento lógico, das ideias nítidas....» Ora, «os nebulosos, por via de regra, cuidam que nos ideólogos não há canto, que não há emoção nos apolíneos; e, chamando ao sonho idealismo, e ao turbilhão profundidade, negam o dom de idealismo, e apodam logo de superficiais, a todos os sacerdotes da ideia clara». O apostolo das «ideias nítidas», que Sérgio indisputavelmente é, adverte, em seguida (para se anteparar contra os que lhe negarem simpatia para poder falar de Raul Brandão - simpatia intelectual, porque a amizade pessoal já os une há muito) que «nunca se suponha.... que o homem de ideias e de espírito crítico não pode simpatizar com o de sentimento»... Mais adiante, o ensaísta, utilizando já uma terminologia que tem pontos de contacto com a nota anónima de nove anos depois na Seara, delineia o molde de uma obra típica de Brandão: «Uma série de desenhos, muitos dos quais inacabados, em atraentes colecções mais ou menos fantasistas, donde se destacam, de quando em quando, águas-fortes alucinadas, impressivíssimas e goiescas, as quais se nos cravam na sensibilidade - na medula do nosso ser - como estudos de mão de mestre para um grande quadro que nos não quis dar; um longo monólogo interior, donde se elevam de espaço a espaço alguns trechos hamléticos de humanidade....» Quanto aos Pescadores, Sérgio, aguardando agora «os grandes livros (e não somente as intensas páginas)», pede ao autor que sejam eles - como os Pastores, e os Operários, e os Lavradores - «a história humilde do nosso povo português (e não só a paisagem em que vive o povo), isto é, que sejam estudados e realizados, não só com os olhos e o colorido de um grande artista que vê aspectos, mas também com aquilo que o assunto exige: o exame generoso de um verdadeiro apóstolo, o sentir pensado de um reformador»».

Oito anos depois, no prefácio (escrito no exílio de Paris) ao terceiro volume dos Ensaios, António Sérgio presta sentida homenagem a Raul Brandão, o companheiro desaparecido dois anos antes. Entre os vários autores de que falara na Lusitânia, "um sobreleva que não tornarei a ver, porque dele a morte nos exilou para sempre»: o autor dos Pescadores. Eu era amigo de Raul Brandão, e seu companheiro na Seara Nova; devia-lhe simpatia, generosidade, louvor: nada disso influiu, no entanto, na imparcialidade crítica com que 
falei dele; e desejo aqui acentuar o facto para poder contrapor à de tantos outros a atitude desse admirável artista, que soube receber com a maior lhaneza - e assentindo, até - o conjunto dos reparos que entendi fazer-lhe».

Estas palavras são anteriores ao mal-estar que a publicação de Vale de Josafat causou nos arraiais republicanos. Não teria António Sérgio razão para enjeitá-las, significativas que eram do entendimento essencial que, para lá dos dissentimentos circunstanciais, sempre se estabelece entre os grandes espíritos, por diferentes que sejam as famílias intelectuais a que pertencem.

\section{AS CARTAS}

(TR. DO MOINHO DE VENTO, 4

Sexta-feira

\section{LISBOA)}

\section{Ex. ${ }^{\mathrm{m}}$ o Presidente}

Muito obrigado pelo cuidado de .a $^{a}$ Ex.a ${ }^{a}$ No n. ${ }^{\circ} 348$ da Seara Nova, p. 180, na nota intitulada Vale de Josafat, poderá encontrar V. ${ }^{a}$ Ex. ${ }^{a}$ o meu comentário aos processos artisticos usados pelo Raul Brandão nas suas Memórias.

Os motivos da publicação dêste $3 .^{\circ}$ tomo foram explicados pelo Camara Reys no Diario Liberal, no momento em que o volume apareceu. O Raul Brandão deixou os seus livros à Seara, que tem a obrigação de os publicar. A impressão do Vaie de Josafat foi adiada até hoje, à espera de melhor oportunidade; sucedeu, porém, que a viuva, a Ex. ${ }^{m}$ a Senhora Dona Angelina, que se sente - e com toda a razão no dever de presidir à edição e de rever as provas, se tomou de mêdo de falecer antes de poder desempenhar-se de tal encargo. Era isso para Senhora um imperioso caso de consciência, que o Camara Reys teve de respeitar. Perante tais circunstâncias, $V .^{\mathbf{a}}$ Ex. ${ }^{\mathrm{a}}$ faria certamente o que êle fez. A vida coloca-nos muitas vezes na necessidade de escolher o menor de dois males.

Afectuosos e agradecidos cumprimentos da Luisa.

De V. Ex. ${ }^{a}$

com toda a consideração

mt. ${ }^{\circ}$ at. $^{\text {to }}$ vnror admirador

António Sérgio 
(Copia)

Em papel timbrado:

HOTEL DEL TECLA

- DE

RAFAEL RODRIGUEZ

HABITACIONES CON CUARTO DE BAÑO

AGUA CORRIENTE EN TODAS LAS HABITACIONES

RESTAURANT

EN LA CIMA DEL MONTE SANTA TECLA

SIEMPRE MARISCOS

TELÉFONO 49

LA GUARDIA

de

1933

(Pontevedra)

\section{Meu Ilustre Correligionário: (Antonio Sergio)}

Não recebi ainda o ultimo numero da «Seara Nova». Mas a minha filha Jeronima, que acaba de chegar, trouxe-me o exemplar do Aquilino. O que diz do genero caricaturista é perfeito, só falta traçar-lhe o limite moral. Ora o ultimo volume das Memorias de Raúl Brandão ultrapassa-o. Não sei mesmo como a «Seara Nova» o editou. Ela tem outra(s) responsabilidade(s), incomparavelmente maior do que as da viuva Chagas. O Raul Brandão conta anedotas falsas, algumas das quais não podem infelismente ser desmentidas pelas pessoas a quem diz que as ouviu *. Mas julgue- [as] pelas palavras que lhe são atribuidas a meu respeito. Espero que lhe não será dificil ter ocasião de as desmentir. Pedimos-lhe a fineza de apresentar os nossos mais dedicados e gratos cumprimentos a sua Ex.ma Esposa de cuja bondade para conosco nunca nos prodere [mos] esquecer. E creia-me saudosamente

\section{Todo seu}

a) Bernardino Machado

* Mas houve pelo menos um caso em que o anedotário de Brandão sobre Bernardino Machado suscitou desmentido. Escreve o memoralista a páginas 62 e 63 do Vale de Josafat:

«Perguntando ao Santos Tavares o que êle [Bernardino] fazia no Brasil, respondeu:

" - Navega. Tem feito imenso. Os monárquicos estão calados. Cortou as crónicas ao Malheiro Dias, que teve de ir trabalhar para uma livraria. Conhece tôda a gente, fala a tôda a gente, maça tôda a gente. Um dia vínhamos por uma avenida fora, eu, êle e a senhora, quando ouvimos um cavalheiro gritar ao longe, de braços abertos:

«-O h querido amigo!...

«-Quem é - perguntei rapidamente ao Bernardino.

"-Não sei...

«Mas já ele o abraçava, sorrindo, apresentando-o à mulher nestes termos:

«- Minha mulher... e... e escuso de te dizer quem êle él» 


\title{
António Sérgio
}

Santos Tavares era o ministro de Portugal em Haia. De passagem por Lisboa, visitou $o$ Século, deixando neste matutino a seguinte carta, publicada a 12 de Outubro de 1933, sob o título

\author{
«AS MEMÓRIAS DE RAUL BRANDÃO \\ - As referências a Bernardino Machado -
}

«Sr. Director: - Recém-chegado a Lisboa, pessoa amiga chama-me a atenção para umas palavras que Raul Brandão me atribuiu, no $3 .^{\circ}$ volume, póstumo, das Memórias - «Vale d Josafat", pag. 62. Repudio-as formalmente tais como ali foram rememoradas, se bem que da sua evidenciada contradição ressaltem, nítidos, os lapsos cometidos.

«Agradecendo a publicação desta carta, creia-me, sr. Director, seu antigo confrade * amigo - (a) E. Santos Tavares.» 